\title{
An introductory report on the effect of use of dextranase-containing mouthwash on oral health status of human volunteers
}

\author{
Nucharee Juntarachot ${ }^{1}$, Bhagavathi Sundaram Sivamaruthi ${ }^{2}$, Sasithorn Sirilun ${ }^{3}$, \\ Piyachat Tongpong $^{4}$, Phakkharawat Sittiprapaporn ${ }^{5}$, Duangporn Kantachote ${ }^{6}$, \\ Chaiyavat Chaiyasut ${ }^{7}$
}

\begin{abstract}
${ }^{1}$ Doctoral Student, ${ }^{2}$ Postdoctoral Research Fellow, ${ }^{3}$ Assistant Professor, ${ }^{7}$ Assistant Professor and Head, Innovation Center for Holistic Health, Nutraceuticals and Cosmeceuticals, Faculty of Pharmacy, Chiang Mai University, Chiang Mai, Thailand ${ }^{4}$ Researcher, Brain Science and Engineering Innovation Research Group, School of Anti-Aging and Regenerative Medicine, Mae Fah Luang University, Bangkok, Thailand, and Department of Anti-Aging Science, School of Anti-Aging and Regenerative Medicine, Mae Fah Luang University, Bangkok, Thailand, ${ }^{5}$ Assistant Professor and Head, Brain Science and Engineering Innovation Research Group, School of Anti-Aging and Regenerative Medicine, Mae Fah Luang University, Bangkok, Thailand, and Department of Anti-Aging Science, School of Anti-Aging and Regenerative Medicine, Mae Fah Luang University, Bangkok, Thailand, ${ }^{6}$ Department of Microbiology, Faculty of Science, Prince of Songkla University, Hat Yai, Thailand
\end{abstract}

Background: Dextran is a branched polysaccharide and one of the polymers, present in the biofilm matrix. The dextran plays a perilous role in dental plaque formation, which is involved in the development of some common oral diseases like dental caries. The dextranhydrolyzing enzymes are under investigation to treat and manage the dental plaques. Aims and Objective: The present study reporting the preliminary observations on the effect of the use of dextranase-containing mouthwash (DMW) on dental plaque and oral health. Materials and Methods: DMW was prepared with food-grade dextranase, preservatives, gelling agents, and water as detailed. Four weeks of experimental design was employed in fourteen healthy volunteers. The selected volunteers were recommended to use DMW for at least twice a day. The plaque index (PI), probing depth (PD), gingival index (GI) and bleeding on probing (BOP) of the volunteer's teeth have been assessed before and after four weeks of DMW use. Results: The volunteers were insisted to use a DMW solution twice a day for four weeks. The $\mathrm{PI}, \mathrm{PD}, \mathrm{GI}$, and BOP was measured before and after the treatment. The plaque index of the subject at baseline and after treatment was $2.22 \pm 0.48$, and $1.88 \pm 0.50$, respectively. PI was significantly reduced after the use of DMW solution for four weeks. The value of PD was 2.00 and 2.00 at baseline and after the use of DMW, respectively. The value of PD was not changed when compared to the baseline values. The sensory evaluation of DMW was performed using questionnaires. Conclusion: The preliminary study results suggested that the use of DMW solution for four weeks (twice a day) notably reduced the PI without any change in PD. However, GI and BOP values were not affected after the use of DMW. The participants, based on the sensory evaluation, accepted the prepared DMW solution. Additional detailed research on the impact of DMW on oral hygiene is needed to confirm the beneficial effects of DMW.

Key words: Dextran; Dextranase-Containing Mouthwash; Oral Health
Access this article online Website:

http://nepjol.info/index.php/AJMS DOI: 10.3126/ajms.v11i1.26499 E-ISSN: 2091-0576 P-ISSN: 2467-9100

\section{INTRODUCTION}

The formation of biofilm on the surface of the tooth is known as dental plaque (DP), which is composed of several microbial strains. Generally, a mixture of microbial cells formed as a polymer matrix includes microbial secretions and salivary compounds characterize DP. ${ }^{1}$ The dental enamel, gingiva, dentin, cementum, mucosa, carious lesion, denture, 
dental implant are vulnerable to oral biofilm formation. The structure and composition of biofilm diverge based on the site of the plaque formation and maturation. ${ }^{2}$ The oral $\mathrm{pH}$, antagonistic substances, availability of nutrients, host defense system are the factors associated with the development and maturation of oral biofilm. ${ }^{3}$

Streptococci, actinomycetes, and Lactobacillus are the commonly found bacterial species in dental biofilm. Streptococcus species are the leading species among the cariogenic bacterial population and have the ability to initiate biofilm formation on clean tooth surfaces ${ }^{3}$. Streptococcus mutans is one of the predominant bacterial pathogens associated with DP formation, which is responsible for the production of the extracellular polysaccharide matrix. The functional and severity of biofilm rely on bacterial composition. ${ }^{1}$

Mostly, the composition and structure of the cariogenic biofilms are not steady, and the composition of the biofilm change drastically based on the availability of nutritional materials. ${ }^{4} S$. mutans is not a permanently principal bacterial species of oral biofilm..$^{5-7}$ However, $S$. mutans is the major matrix maker. In the presence of starch and sucrose, $S$. mutans can rapidly amend the development of cariogenic biofilms. ${ }^{4,8,9}$

Dextran is a branched polysaccharide and one of the polymers, present in the biofilm matrix. The dextran plays a perilous role in dental plaque formation, which is involved in the development of some common oral diseases like dental caries. The enzyme that hydrolase the $\alpha-(1-6)$-d-glycoside linkages in dextran called dextranase. ${ }^{10}$ The dextran-hydrolyzing enzymes are under investigation to treat and manage the dental plaques. ${ }^{11}$ The present study reporting the preliminary observations on the effect of the use of dextranase-containing mouthwash (DMW) on dental plaque and oral health.

\section{MATERIALS AND METHODS}

\section{Preparation of DIMW}

DMW was prepared with food-grade dextranase, preservatives, gelling agents, and water as detailed (Table. 1).

\section{Subjects and experimentation}

Four weeks of experimental design was employed in fourteen healthy volunteers. The selected volunteers were recommended to use DMW for at least twice a day. The plaque index $(\mathrm{PI})$, probing depth $(\mathrm{PD})$, gingival index $(\mathrm{GI})$ and bleeding on probing (BOP) of the volunteer's teeth have been assessed before and after four weeks of DMW use (Table 2).

\section{Inclusion criteria}

- Volunteers must be more than 18 years old

- The volunteer has clinically recognized plaque and/or gingivitis

\begin{tabular}{ll} 
Table 1: The composition of mouthwash \\
\hline Phase & Ingredients \\
\hline A & Preservative \\
& Sweetener \\
& Gelling agent \\
& $\mathrm{H}_{2} \mathrm{O}$ \\
B & Dextranase \\
C & Flavoring agent \\
D & Gel-forming agent \\
& $\mathrm{H}_{2} \mathrm{O}$ \\
\hline
\end{tabular}

\begin{tabular}{lll}
$\begin{array}{l}\text { Table 2: Gingival index and Bleeding on probing } \\
\text { index }\end{array}$ & \\
\hline Index & Before DMW use & After DMW use \\
\hline Gingival index & No inflammation & No inflammation \\
Bleeding on probing & No bleeding & No bleeding \\
\hline
\end{tabular}

- The volunteer should have Periodontal Screening and Recording (PSR) Scores of 0-2

- No antibiotic use for at least the last 1 month at the time of the experiment

- The volunteer should be a non-smoker

- The volunteer should give informed consent.

\section{Exclusion criteria}

- Volunteers with systemic diseases such as diabetes, heart diseases, etc.

- Volunteers with blood-associated diseases

- Volunteers have tissue disease in teeth or dead teeth

- Pregnant and breastfeeding women.

\section{Skin irritation test}

$2.0 \mu \mathrm{l}$ of mouthwash was applied on small area $(2 \times 2 \mathrm{~cm})$ of the upper arm and left for $24 \mathrm{~h}$. After $24 \mathrm{~h}$, the sites were examined for irritation, and formation of edema and erythema. ${ }^{12,13}$

Measurement of plaque index (PI), probing depth (PD), gingival index (Gl)and bleeding on probing (BOP)

The PI, PD, GI, and BOP scores of the subjects before and after four weeks of experiments were recorded as detailed previously by Feier et al. ${ }^{14}$, Gupta et al. ${ }^{15}$, Gopinath et al. ${ }^{16}$, and Checchiet al. ${ }^{17}$, respectively.

\section{The sensory test}

The acceptability of the DMW solution was assessed by sensory analysis. The parameters include color, odor, flavor, distribution, homogeneity, stickiness, time for coating of mouthwash, clean feeling after cleansing, fresh feeling after use, ability to remove plaque, ease of use, overall satisfactionhave been measured. A 5-point hedonic scale, where 0 - dislike extremely; 1 - dislike slightly; 2- neither like 
nor dislike; 3- like slightly and 4- like extremely was used to assess the suitability. ${ }^{18}$

\section{Statistical analysis}

The results were evaluated using STATA15, and the paired t-test was performed to determine the statistical difference between before and after-treatment values.

\section{RESULTS}

The volunteers were insisted to use a DMW solution twice a day for four weeks. The PI, PD, GI, and BOP was measured before and after the treatment (Table 2). The plaque index of the subject at baseline and after treatment was $2.22 \pm$ 0.48 , and $1.88 \pm 0.50$, respectively. PI was significantly reduced after the use of DMW solution for four weeks (Figure 1). The value of PD was 2.00 and 2.00 at baseline and after the use of DMW, respectively. The value of PD was not changed when compared to the baseline values (Figure 2).The status of dental plaque after the use of DMW has been represented in figure 3. The sensory evaluation of DMW was performed using questionnaires. The results of the sensory evaluation were represented in figure 4 .

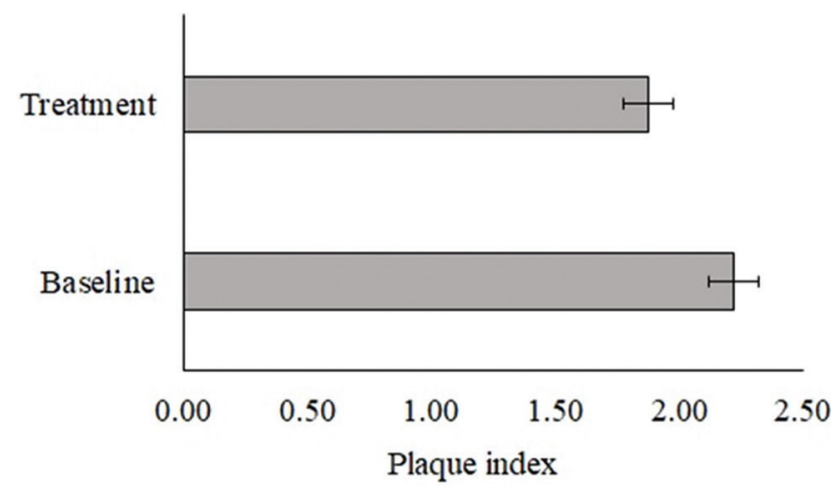

Figure 1: The change in plaque index of the subjects after four weeks of use of DMW. The results were represented as the mean \pm standard error.

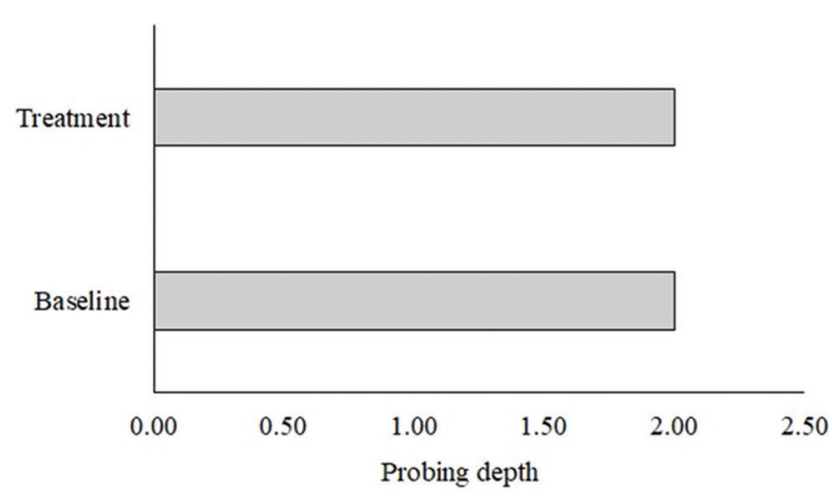

Figure 2: The change in probing the depth of the subjects after four weeks of use of DMW. The results were represented as the mean \pm standard error.

\section{DISCUSSION}

Very limited reports are available on the effects of medicated mouthwash solutions on oral hygiene. The use of neem extract-based mouthwash solution significantly reduced the PI and GI in children after twenty-one days of use. ${ }^{19}$ Likely, the use of Garcinia mangostana L. pericarp extract containing gel enhanced the periodontal treatment, significantly. ${ }^{20}$

The efficacy of the DMW solution was reported previously. The mouthwash preparation with Lipomyces statkeyi KSM22 dextranase exhibited anti-plaque activity ${ }^{21}$ and DMW reduced the plaque adhesion after seven days of use. ${ }^{22}$

The results of the current study showed that the use of DMW improved the PI, and has not affected the PD. The GI and BOP values were not affected after the use of DMW. The sensory evaluation study reported that volunteers moderately liked the DMW. The results suggested that the use of DMW could improve the oral hygiene of the volunteers.

\section{CONCLUSION}

The preliminary study results suggested that the use of DMW solution for four weeks (twice a day) notably reduced the PI without any change in PD. However, GI and BOP

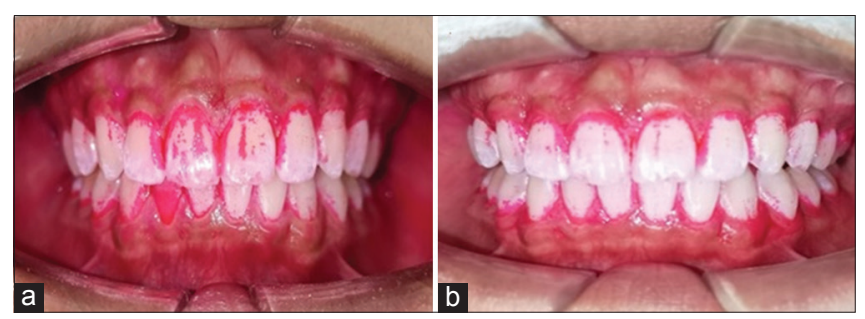

Figure 3: The change in the appearance of dental plaques after the use of DMW solution. A. baseline, B. After 4-weeks of treatment.

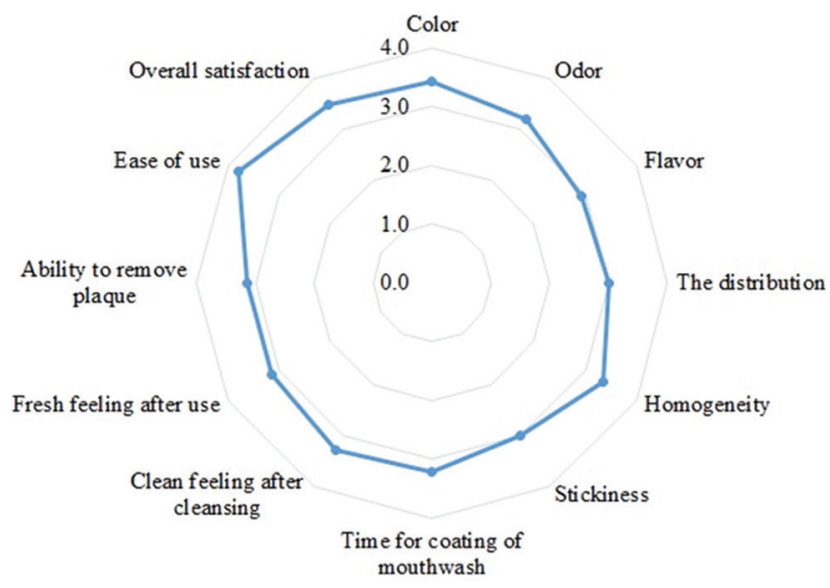

Figure 4: The sensory response of volunteers against DMW. 
values were not affected after the use of DMW. The participants, based on the sensory evaluation, accepted the prepared DMW solution. Additional detailed research on the impact of DMW on oral hygiene is needed to confirm the beneficial effects of DMW.

\section{ACKNOWLEDGEMENT}

The authors would like to acknowledge the Thailand Research Fund (TRF), Supporting Research Funds for Industries (SURF) (Grant no. RDG58I0002), for the support. The authors gratefully acknowledge the Chiang Mai University grant (CMU-grant) for the support. Authors also gratefully acknowledge Brain Science and Engineering Innovation Research Group, Mae Fah Luang University grant (2019) (MFU-grant no. 611U109005) and 2020, Thailand for the support.

\section{REFERENCES}

1 Yu OY, Zhao IS, Mei ML, Lo EC and Chu CH. Dental biofilm and laboratory microbial culture models for cariology research. Dent J (Basel) 2017; 5: 21.

2. Marsh $P$ and Martin $M$. Marsh and Martin's oral microbiology. $6^{\text {th }}$ ed. Edinburgh, UK: Elsevier, 2016, pp. 81-111.

3. Sumney DL and Jordan HV. Characterization of bacteria isolated from human root surface carious lesions. J Dent Res 1974; 53: 343-351.

4. Marsh PD. Are dental diseases examples of ecological catastrophes? Microbiology 2003; 149: 279-294.

5. Takahashi $\mathrm{N}$ and Nyvad B. The role of bacteria in the caries process: ecological perspectives. J Dent Res 2011; 90: 294-303.

6. Valm AM, Mark Welch JL, Rieken CW, Hasegawa Y, Sogin ML, Oldenbourg R, et al. Systems-level analysis of microbial community organization through combinatorial labeling and spectral imaging. Proc Natl Acad Sci USA 2011; 108: 4152-4157.

7. Mattos-Graner RO, Klein MI and Smith DJ. Lessons learned from clinical studies: roles of mutans streptococci in the pathogenesis of dental caries. Curr Oral Health Rep 2014; 1: 70-78.

8. Ribeiro CC, Tabchoury CP, Del Bel Cury AA, Tenuta LM, Rosalen PL and Cury JA. Effect of starch on the cariogenic potential of sucrose. Br J Nutr 2005; 94: 44-50.

9. Paes Leme F, Koo H, Bellato CM, Bedi G and Cury JA. The role of sucrose in cariogenic dental biofilm formation-new insight. $J$ Dent Res 2006; 85: 878-887.

10. Wang DL, Lu MS, Wang SJ, Jiao YL, Li WJ, Zhu Q, et al. Purification and characterization of a novel marine Arthrobacter oxydans KQ11 dextranase. Carbohydr Polym 2014; 106: 71-76.

11. Khalikova E, Susi $P$ and Korpela T. Microbial dextran hydrolyzing enzymes: fundamentals and applications. Microbiol. Mol Biol Rev 2005; 69: 306-325.

12. Frosch PJ, Geier J, Uter W and Goossens A. Patch testing with patients own products. In: Frosch Menne, Lepoittevin, eds. Contact Dermatitis. $4^{\text {th }}$ ed. Berlin: Springer, 2006, 929-942.

13. Choi SY, Seop SY, Hyun MY, Yoo KH, Kim BJ, Kim MN, et al. Safety evaluation of topical valproate application.Toxicol Res 2013;29: 87-90.

14. Feier I, Onisei D and Onisei D. The plurivalence of the interpretation of correlation between plaque score and bleeding score. J Romanian Med Dent 2009; 13: 45-48.

15. Gupta N, Rath SK and Lohra P. Comparative evaluation of accuracy of periodontal probing depth and attachment levels using a Florida probe versus traditional probes. Med J Armed Forces India 2015; 71: 352-358.

16. Gopinath VK, Rahman B and Awad MA. Assessment of gingival health among school children in Sharjah, United Arab Emirates. Eur J Dent 2015; 9: 36-40.

17. Checchi L, Montevecchi M, Checchi V and Zappulla F. The relationship between bleeding on probing and subgingival deposits. An endoscopical evaluation. Open Dent J 2009; 3: 154-160.

18. Graham JO, Agbenorhevi JK and Kpodo FM. Total phenol content and antioxidant activity of okra seeds from different genotypes. Am J Food Nutr 2017; 5: 90-94.

19. Sharma R, Hebbal M, Ankola AV, Murugaboopathy $V$ and Shetty SJ. Effect of two herbal mouthwashes on gingival health of schoolchildren. J Tradit Complement Med 2014; 4: 272-278.

20. Rassameemasmaung S, Sirikulsathean A, Amornchat C, Maungmingsook P, Rojanapanthu P and Gritsanaphan W. Topical application of Garcinia mangostana L. pericarp gel as an adjunct to periodontal treatment. Complement Ther Med 2008; 16: 262-267.

21. Son EJ, Kim YJ, Kim DM and Chung HJ. The effect of dextranase-containing mouthwash in human experimental gingivitis. J Korean Acad Periodontol 2001; 31: 401-420

22. Matsumoto M, Fukai T, Yasui T, Mukasa $\mathrm{K}$ and Kaneko $\mathrm{K}$. Inhibition of plaque adhesion by dextranase-containing mouth rinse. J Dent HIth 2004; 54: 208-215.

\footnotetext{
Authors Contribution:

NJ- Concept and design of the study, statistically analyzed and interpreted, manuscript preparation; BSS- Statistically analyzed and interpreted, manuscript preparation, critical revision of the manuscript; SS- Concept and design of the study, statistically analyzed and interpreted; PT- Concept and design of the study; PS- Manuscript preparation, critical revision of the manuscript; DK- Concept and design of the study; CC- Concept and design of the study, statistically analyzed and interpreted, manuscript preparation, critical revision of the manuscript

Work attributed to:

nnovation Center for Holistic Health, Nutraceuticals and Cosmeceuticals, Faculty of Pharmacy, Chiang Mai University, Thailand;

Brain Science and Engineering Innovation Research Group, School of Anti-Aging and Regenerative Medicine, Mae Fah Luang University, Thailand.

Orcid ID:

Ms. Nucharee Juntarachot-1 $\mathrm{https://orcid.org/0000-0003-4088-6654}$

Dr. Bhagavathi Sundaram Sivamaruthi-(i) https://orcid.org/0000-0002-5499-8350

Dr. Sasithorn Sirilun-10 https://orcid.org/0000-0002-1508-2358

Dr. Piyachat Tongpong- https://orcid.org/0000-0003-2630-809X

Dr. Phakkharawat Sittiprapaporn-D https://orcid.org/0000-0002-4103-9396

Dr. Duangporn Kantachote- 1 https://orcid.org/0000-0003-2010-5988

Dr. Chaiyavat Chaiyasut- https://orcid.org/0000-0002-1633-2419

Source of Support: Thailand Research Fund (TRF), Supporting Research Funds for Industries (SURF) (Grant no. RDG5810002); Chiang Mai University grant (CMU-grant), Thailand; Brain Science and Engineering Innovation Research Group, Mae Fah Luang University grant (2019) (MFU-grant no. 611U109005) and 2020, Thailand, Conflict of Interest: None.
} 